\title{
ON A HEAT AND MASS TRANSFER MODEL FOR THE LOCALLY INHOMOGENEOUS INITIAL DATA
}

\author{
T.Sh. Kal'menov, Institute of Mathematics and Mathematical Modelling, Almaty, \\ Kazakhstan, kalmenov@math.kz, \\ G.D. Arepova, Institute of Mathematics and Mathematical Modelling, Almaty, \\ Kazakhstan, arepova@math.kz
}

\begin{abstract}
We consider a model case of the problem of heat diffusion in a homogeneous body with a special initial state. The peculiarity of this initial state is its local inhomogeneity. That is, there is a closed domain $\Omega$ inside a body, the initial state is constant out of the domain. Mathematical modelling leads to the problem for a homogeneous multi-dimensional diffusion equation. We construct the boundary conditions on the boundary of the domain $\Omega$, which can be characterized as "transparent" boundary conditions. We separately consider a special case - a model of redistribution of heat in a uniform linear rod, the side surface of which is insulated in the absence of (internal and external) sources of heat and of locally inhomogeneous initial state.
\end{abstract}

Keywords: diffusion equation; homogeneous body; initial state; local inhomogeneity; transparent boundary conditions.

Introduction. It is well known that the heat transfer process inside the solid body is a transfer of energy, taking place between different sections of the bodies and having different temperatures. In practice, while considering "calm" processes, from the three methods of heat distribution (thermal conductivity, convection and thermal radiation) it is sufficient to consider only the thermal conductivity (diffusion).

Heat conduction and diffusion problems have wide practical application. The ability to model and solve such problems provides obtaining important information about the process. Modelling of processes described by the heat equation is the seriously researched field of mathematical modelling. However, as the model problems with classic initialboundary conditions are usually used. Using of non-local boundary conditions although sometimes allows describing the processes more accurately but significantly complicates the mathematical models. Thereby the study of mathematical models of thermal conductivity with non-local initial-boundary conditions is a relevant problem.

The aim of this paper is to demonstrate the using of non-local boundary conditions of complex (integral) form for modelling a special case of heat transfer problems with a special initial state. The peculiarity of this initial state is its local inhomogeneity. That is, there is a closed domain $\Omega$ inside the body, the initial state is constant out of the domain.

We demonstrate a general idea of the considered problem on a simple example of one-dimensional heat conduction. As a model body we choose a uniform linear rod, the side surface of which does not conduct heat (insulated) in the absence of (internal and external) sources of heat. It's clear that if at the initial time the rod is heated unevenly then there will be a redistribution of heat and its temperature is eventually equalized. In case when in the selected dimensionless coordinates the length of the rod is large enough, then the process is described by the classical initial problem for the heat equation in a 
half-plane $\mathbb{R}_{+}^{2}=\{-\infty<x<\infty, t>0\}$

$$
\begin{gathered}
\frac{\partial}{\partial t} u(x, t)-a^{2} \frac{\partial^{2}}{\partial x^{2}} u(x, t)=0, \\
u(x, 0)=u_{0}(x),-\infty<x<\infty,
\end{gathered}
$$

where $a$ is a heat coefficient, and $u_{0}(x)$ is an initial temperature distribution.

The solution of problem (1) - (2) exists, is unique and expressed by the surface potential

$$
u(x, t)=\frac{1}{2 a \sqrt{\pi t}} \int_{-\infty}^{\infty} e^{-\frac{(x-\xi)^{2}}{4 a^{2} t}} u_{0}(\xi) d \xi
$$

We consider a special case of the problem when the initial state is locally inhomogeneous. For our case it means that in the selected dimensionless coordinates the initial state $u_{0}(x) \equiv 0$ out of the interval $x \in(0,1)$. Then from (3) we obtain the solution of problem $(1)-(2)$ in this particular case

$$
u(x, t)=\frac{1}{2 a \sqrt{\pi t}} \int_{0}^{1} e^{-\frac{(x-\xi)^{2}}{4 a^{2} t}} u_{0}(\xi) d \xi
$$

In practice we often have to deal with problems in which we are interested in the distribution of temperature only in a single piece of the rod, it is logical to consider the heat problem only in a limited segment of the rod $0 \leq x \leq 1$ for $t \geq 0$. Thereby we come to the consideration of equation (1) in a domain $D=\{0<x<1, t>0\}$ bounded with space variables, with initial condition (2). For unique definition of a solution in $D$ it's necessary to set additionally the boundary conditions on the boundary of the cylinder $\partial D \times(t \geq 0)$. For our case it is necessary to set additionally the boundary conditions at $x=0$ and $x=1$ for all $t \geq 0$.

Therefore, there arises a problem of defining of such boundary conditions for equation (1) with the initial condition (2), which uniquely define the solution in the form (4). These boundary conditions must provide possibility for such smooth continuation of the solution beyond the spatial boundaries of $D$, that the continued function is also a solution of the heat equation (1). Such boundary conditions are called "transparent boundary conditions".

In our work [1] we constructed boundary conditions for a volume harmonic potential. As it turned out, these boundary conditions describe the long known in theoretical physics effect of "transparent boundary conditions", skipping outgoing waves and reflecting the incoming waves [2]. The existence of such boundary conditions of the volume potential allows reducing the problem of Sommerfeld radiation conditions in infinite domain to a problem in a bounded domain and using effectively the numerical methods [3]. This boundary condition was successfully used to compute in explicit form of eigenvalues and eigenfunctions of the volume potential in the ball [1, 2]. In [4] a boundary condition of the heat volume potential in not cylindrical domain was constructed. In [5] we considered the questions about constructing of the boundary conditions for integral operators in the general form. In all these works the questions of constructing of boundary conditions for functions being the solutions of inhomogeneous equations were considered. Unlike the above-mentioned works in this article we consider the case of a non-homogeneous differential equation. 
1. Formulation of the Problem. Let $\Omega \subset \mathbb{R}^{n}$ be a bounded domain with sufficiently smooth boundary $\partial \Omega$. By $D$ denote a cylindrical domain $D=\Omega \times(0, T)$. In $D$ consider a surface heat potential

$$
u=\int_{\Omega} \varepsilon_{n}(x-\xi, t) u_{0}(\xi) d \xi
$$

where $\varepsilon_{n}(x, t)$ is a fundamental solution of the heat equation

$$
\diamond u \equiv\left(\frac{\partial}{\partial t}-a^{2} \triangle_{x}\right) u=0
$$

which has the form [6, p. 199]

$$
\varepsilon_{n}(x, t)=\frac{\theta(t)}{(2 a \sqrt{\pi t})^{n}} e^{-\frac{|x|^{2}}{4 a^{2} t}} .
$$

It is well known that for $u_{0} \in C(\bar{\Omega}),\left.u_{0}\right|_{\partial \Omega}=0$, the surface heat potential (5) in domain $D$ is infinitely differentiable function, $u \in C(\bar{D})$ and satisfies equation (6) and the initial condition

$$
u(x, 0)=u_{0}(x), x \in \Omega .
$$

Naturally there arises a question on boundary conditions of the surface potential. That is, it is necessary to find additional conditions (not dependent on $u_{0}(x)$ ), which uniquely define function (5) together with equation (6) and the initial condition (7).

\section{Formulation and Proof of the Main result}

Theorem 1. Let $u_{0} \in C^{2+\beta}(\bar{\Omega})$ and

$$
\left.u_{0}\right|_{\partial \Omega}=0,\left.\quad \frac{\partial u_{0}}{\partial \nu}\right|_{\partial \Omega}=0,\left.\quad \frac{\partial^{2} u_{0}}{\partial \nu^{2}}\right|_{\partial \Omega}=0 .
$$

Then the surface heat potential (5) satisfies the lateral boundary condition

$$
\frac{u(x, t)}{2}-a^{2} \int_{0}^{t} d \tau \int_{\partial \Omega}\left(\frac{\partial \varepsilon_{n}}{\partial \nu_{\xi}}(x-\xi, t-\tau) u(\xi, \tau)-\varepsilon_{n}(x-\xi, t-\tau) \frac{\partial u}{\partial \nu_{\xi}}(\xi, \tau)\right) d S_{\xi}=0
$$

where $x \in \partial \Omega, t \in[0, T], \frac{\partial}{\partial \nu_{\xi}}$ denotes a normal derivative on $\partial \Omega$ (on the direction of the outer normal in respect to the volume $D$ normal).

Conversely, if $u(x, t) \in C^{2+\beta, 1+\beta}(\bar{D})$ is a classical solution of (6), satisfying the initial condition (7) and the lateral boundary condition (8), then $u(x, t)$ is uniquely defined and it is given in the form of the surface potential (5).

Proof. By direct calculation at $x \in \Omega, t \in(0, T), \delta>0$ it is easy to see that the identities are valid

$$
\begin{aligned}
& \int_{0}^{t-\delta} d \tau \int_{\Omega} \varepsilon_{n}(x-\xi, t-\tau) \diamond_{\xi, \tau} u(\xi, \tau) d \xi=\int_{\Omega} \varepsilon_{n}(x-\xi, \delta) u(\xi, t-\delta) d \xi-\int_{\Omega} \varepsilon_{n}(x-\xi, t) u(\xi, 0) d \xi+ \\
& \quad+a^{2} \int_{0}^{t-\delta} d \tau \int_{\partial \Omega}\left(u(\xi, \tau) \frac{\partial}{\partial \nu_{\xi}} \varepsilon_{n}(x-\xi, t-\tau)-\varepsilon_{n}(x-\xi, t-\tau) \frac{\partial}{\partial \nu_{\xi}} u(\xi, \tau)\right) d S_{\xi} .
\end{aligned}
$$


By virtue of that

$$
\lim _{\delta \rightarrow 0} \int_{\Omega} \varepsilon_{n}(x-\xi, \delta) u(\xi, t-\delta) d \xi=u(x, t),
$$

taking into account (6) and (7), for the surface potential (5) at $\delta \rightarrow 0$ from (9) we obtain the identity

$$
a^{2} \int_{0}^{t-\delta} d \tau \int_{\partial \Omega}\left(u(\xi, \tau) \frac{\partial}{\partial \nu_{\xi}} \varepsilon_{n}(x-\xi, t-\tau)-\varepsilon_{n}(x-\xi, t-\tau) \frac{\partial}{\partial \nu_{\xi}} u(\xi, \tau)\right) d S_{\xi}=0,
$$

being valid for all $(x, t) \in D$. Now, passing to the limit at $x \rightarrow \partial \Omega$ and using the property of potential jump on the boundary, from (10) we get (8).

Conversely, we show that the classical solution of (6), satisfying the initial condition (7) and the lateral boundary condition (8), is unique. Let $U \in C^{2+\beta, 1+\beta}(\bar{D})$ be a solution of $(6)-(8)$ with the homogeneous initial condition $(7)$.

For such solution from (9) at $\delta \rightarrow 0$ we get the identity

$U(x, t)+a^{2} \int_{0}^{t} d \tau \int_{\partial \Omega}\left(U(\xi, \tau) \frac{\partial}{\partial \nu_{\xi}} \varepsilon_{n}(x-\xi, t-\tau)-\varepsilon_{n}(x-\xi, t-\tau) \frac{\partial}{\partial \nu_{\xi}} U(\xi, \tau)\right) d S_{\xi}=0$,

valid for all $(x, t) \in D$. Now, passing to the limit at $x \rightarrow \partial \Omega$, taking into account the boundary condition (8), we obtain, that $\left.U\right|_{\partial \Omega}=0$. Consequently, $U(x, t)$ is the solution of the first initial-boundary problem for the heat equation in $D$ with homogeneous data. By virtue of the uniqueness of its solution we obtain that $U(x, t) \equiv 0$. Therefore the classical solution of equation (6), satisfying the initial condition (7) and the lateral boundary condition (8) is unique.

The theorem is proved.

3. One-Dimensional Case. Consider a special case of the one-dimensional heat potential (4) in domain $D=\{0<x<1, t>0\}$, with the initial condition (2). For unique definition of the solution of the heat equation (1) in $D$ from Theorem 1 we find boundary conditions on the boundary: when $x=0$ and $x=1$ for all $t \geq 0$. In this case the boundary of the domain $\Omega$ is doubly connected and the integral by the boundary turns into a sum of two summands.

In one-dimensional case the fundamental solution of (1) has the form

$$
\varepsilon_{1}(x-\xi, t-\tau)=\frac{\theta(t)}{2 a \sqrt{\pi(t-\tau)}} e^{-\frac{(x-\xi)^{2}}{4 a^{2}(t-\tau)}} .
$$

Computing

$$
\frac{\partial}{\partial \xi} \varepsilon_{1}(x-\xi, t-\tau)=\theta(t) \frac{x-\xi}{4 a^{3} \sqrt{\pi}(t-\tau)^{3 / 2}} e^{-\frac{(x-\xi)^{2}}{4 a^{2}(t-\tau)}} .
$$

It is easy to see that

$$
\left.\frac{\partial}{\partial \xi} \varepsilon_{1}(x-\xi, t-\tau)\right|_{x=\xi}=0
$$

Now as the

$$
\left.\frac{\partial}{\partial \nu_{\xi}}\right|_{\xi=0}=-\left.\frac{\partial}{\partial \xi}\right|_{\xi=0},\left.\quad \frac{\partial}{\partial \nu_{\xi}}\right|_{\xi=1}=\left.\frac{\partial}{\partial \xi}\right|_{\xi=1}
$$


then the boundary conditions (8) have the form

$$
\begin{aligned}
& u(0, t)-a \int_{0}^{t} \frac{1}{\sqrt{\pi(t-\tau)}} u_{x}(0, \tau) d \tau+a \int_{0}^{t} \frac{e^{-\frac{1}{4 a^{2}(t-\tau)}}}{\sqrt{\pi(t-\tau)}}\left(\frac{u(1, \tau)}{2 a^{2}(t-\tau)}+u_{x}(1, \tau)\right) d \tau=0, \\
& u(1, t)-a \int_{0}^{t} \frac{1}{\sqrt{\pi(t-\tau)}} u_{x}(1, \tau) d \tau+a \int_{0}^{t} \frac{e^{-\frac{1}{4 a^{2}(t-\tau)}}}{\sqrt{\pi(t-\tau)}}\left(\frac{u(0, \tau)}{2 a^{2}(t-\tau)}+u_{x}(0, \tau)\right) d \tau=0 .
\end{aligned}
$$

Thus, the model of heat redistribution in one-dimensional rod, the side surface of which is insulated, in the absence of (internal and external) sources of heat and locally inhomogeneous initial state is described by the initial-boundary problem for the heat equation (1) in the domain $D=\{0<x<1, t>0\}$, with initial condition (2) and the non-local boundary conditions (12) and (13). This initial-boundary value problem is correct, that is, its solution exists, is unique and is represented by the surface potential (4).

Conclusion. In this work we have considered one mathematical problem, arising in modelling of the process of the heat redistribution in a homogeneous solid body. The peculiarity of the initial state is its local inhomogeneity. This inhomogeneity has been characterized by the fact that in the selected dimensionless coordinates the domain, the initial state of which is nonzero (we denote it by $\Omega$ ), is small with respect to the total volume of the body. The consideration has been reduced to the initial-boundary value problem for the heat equation in a cylindrical domain $\Omega \times(0, T)$ with nonlocal (integral form) boundary conditions by spatial variables. These founded non-local boundary conditions describe the well known in theoretical physics effect of "transparent boundary conditions", which skip the heat diffusion through the boundary without restrictions.

Acknowledgements. The authors express their gratitude to Prof. Sergey Pyatkov and Prof. Makhmud Sadybekov for valuable advices during the work. Research supported by the grant 4075/GF4 of the Ministry of Education and Science of Republic of Kazakhstan.

\section{References}

1. Kal'menov T.Sh., Suragan D. On Spectral Problems for the Volume Potential. Doklady Mathematics, 2009, vol. 80, no. 2, pp. 646-649. DOI: 10.1134/S1064562409050032

2. Kal'menov T.Sh., Suragan D. A Boundary Condition and Spectral Problems for the Newton Potential. Operator Theory: Advances and Applications, 2010, vol. 216, pp. 187-210.

3. Kal'menov T.Sh., Suragan D. Transfer of Sommerfeld Radiation Conditions to the Boundary of a Bounded Domain. Computational Mathematics and Mathematical Physics, 2012, vol. 52, no. 6, pp. 1063-1068. (in Russian)

4. Kal'menov T.Sh., Tokmagambetov N.E. On a Nonlocal Boundary Value Problem for the Multidimensional Heat Equation in a Noncylindrical Domain. Siberian Mathematical Journal, 2013, vol. 54, no. 6, pp. 1023-1028. DOI: 10.1134/S0037446613060086

5. Kal'menov T.Sh., Arepova G.D. [On Boundary Onditions for the Linear Integral Operators]. Doklady Adygeyskoy (Cherkesskoy) mezhdunarodnoy akademii nauk [Reports of Adyghe (Circassian) International Academy of Sciences], 2015, vol. 17, no. 4, pp. 34-41. 
6. Vladimirov V.S. Equations of Mathematical Physics. Moscow, Nauka, 1976.

Received February 28, 2016

УДК 517.958

DOI: $10.14529 / \mathrm{mmp} 160212$

\title{
ОБ ОДНОЙ МОДЕЛИ ТЕПЛОМАССОПЕРЕНОСА ПРИ ЛОКАЛЬНО НЕОДНОРОДНЫХ НАЧАЛЬНЫХ ДАННЫХ
}

\author{
Т.Ш. Калъменов, Г.Д. Арепова
}

Рассматривается модельный случай задачи о тепловой диффузии в однородном теле, при специальном начальном состоянии. Особенностью этого начального состояния является его локальная неоднородность. То есть внутри тела имеется замкнутая область $\Omega$, вне которой начальное состояние является постоянным. Математическое моделирование приводит к задаче для однородного многомерного уравнения диффузии. Построены краевые условия на границе области $\Omega$, которые можно характеризовать, как «прозрачные», краевые условия. Отдельно рассмотрен частный случай - модель перераспределения тепла в однородном линейном стержне, боковая поверхность которого теплоизолирована, при отсутствии (внутренних и внешних) источников тепла и при локально неоднородном начальном состоянии.

Ключевые слова: уравнение диффузии; однородное тело; начальное состояние; локальная неоднородность; прозрачные краевые условия.

\section{Литература}

1. Кальменов, Т.Ш. К спектральным вопросам объемного потенциала / Т.Ш. Кальменов, Д. Сураган // Доклады академии наук России. - 2009. - Т. 428, № 4. - С. 16-19.

2. Kal'menov, T.Sh. A Boundary Condition and Spectral Problems for the Newton Potential / T.Sh. Kal'menov, D. Suragan // Operator Theory: Advances and Applications. - 2010. V. 216. - P. 187-210.

3. Кальменов, Т.Ш. Перенос условий излучения Зоммерфельда на границу ограниченной области / Т.Ш. Кальменов, Д. Сураган // Журнал вычислительной математики и математической физики. - 2012. - Т. 52, № 6. - С. 1063-1068.

4. Кальменов, Т.Ш. Об одной нелокальной краевой задаче для многомерного уравнения теплопроводности в нецилиндрической области / Т.Ш. Кальменов, Н.Е. Токмагамбетов // Сибирский математический журнал. - 2013. - Т. 54, № 6. - С. 1287-1293.

5. Кальменов, Т.Ш. О граничных условиях линейных интегральных операторов Т.Ш. Кальменов, Г.Д. Арепова // Доклады АМАН. - 2015. - Т. 17, № 4. - С. 34-41.

6. Владимиров, В.С. Уравнения математической физики / В.С. Владимиров. - М.: Наука. $-1981 .-512$ c.

Тынысбек Шарипович Кальменов, доктор физико-математических наук, професcop, академик Национальной академии наук Республики Казахстан, генеральный директор, Институт математики и математического моделирования (г. Алматы, Казахстан), kalmenov@math.kz.

Гаухар Джумабаевна Арепова, докторант, Институт математики и математического моделирования (г. Алматы, Казахстан), arepova@math.kz.

Поступила в редакцию 28 февраля 2016 г.

Вестник ЮУрГУ. Серия «Математическое моделирование

и программирование» (Вестник ЮУрГУ ММП). 2016. Т. 9, № 2. С. 124-129 